\title{
Imágenes de la vejez: ¿mitos o realidades?
}

Neyda Ma. Mendoza Ruvalcaba ${ }^{1}$ y Elva Dolores Arias Merino²

\section{Introducción}

Los estereotipos negativos hacia la vejez representan ideas generales acerca del proceso de envejecimiento e incluyen las nociones de que el envejecimiento es lo mismo que enfermedad, discapacidad y, en general, deterioro de la salud física, capacidades mentales (por ejemplo las cognitivas) y sociales. Éstas no sólo son imprecisas, sino que tienen un impacto negativo en el bienestar de las personas mayores (Sindi et al., 2012).

Los estereotipos hacia la vejez constituyen ideas erróneas al asumir que el grupo de adultos mayores es homogéneo, es decir, que no toma en consideración la demostrada variabilidad y heterogeneidad en el estado de salud asociado a la edad (Ory, Kinney Hoffman, Hawkins, Sanner, y Mockenhaupt, 2003).

Las ideas negativas en torno a la vejez juegan un rol importante en la formación de la autopercepción de los adultos

1 Universidad de Guadalajara cutonALA.

2 Universidad de Guadalajara cucs 
mayores acerca de su propio proceso de envejecimiento (Levy, Slade y Kasl, 2002), es decir, que pueden potencialmente convertirse en una "profesía autocumplida" que llevan a la persona mayor que comparte e internaliza estas ideas negativas hacia un decremento en sus habilidades cognitivas, emocionales, confianza y autoimagen.

El propósito de este estudio es contrastar los estereotipos e imágenes comunes acerca de la vejez y la edad con la situación actual de las personas mayores en lo que refiere a la salud, funcionalidad, estado cognitivo, anímico y productividad.

\section{Método}

\section{Participantes}

Estudio transversal de metodología cuantitativa. Previo consentimiento informado se entrevistó a un total de 638 mujeres de 60 años y más que asistían a centros de día del Sistema DIF Guadalajara.

La edad promedio de las participantes fue 70.9 (DE 2.7) años con un rango entre 60 y 95 años. Respecto al estado civil, $47.8 \%$ eran viudas, $32 \%$ casadas, $10 \%$ solteras, $9.7 \%$ divorciadas o separadas. La gran mayoría asistió a la escuela (84.6\%); sin embargo, casi la mitad (45.6\%) tenía baja escolaridad, con un promedio de años de estudio de 4.45 (DE 3.62) años, la mayoría sabía leer y escribir (89.2\%).

\section{Material}

Las evaluaciones se condujeron por entrevistadores previamente entrenados y se llevaron a cabo en el sitio de reunión del grupo de adultos mayores al que asistían semanalmente. La batería de evaluación incluyó datos sociodemográficos, autoinforme de estilo de vida y actividades, así como pruebas para valorar: capacidad funcional para realizar las actividades básicas e instrumentales de la vida diaria con el índice de Barthel (Mahoney y 
Barthel, 1965) y la Escala Lawton (Lawton y Brody, 1969), respectivamente, estado cognitivo con el Mini-Mental State Examination (Folstein, Folstein y McHugh, 1975) en su versión para población mexicana, depresión con la Geriatric Depression Scale (Yesavage et al., 1983), así como un autoinforme de salud. Adicionalmente, se valoró a través de un autoinforme la satisfacción con la vida y la autopercepción de salud.

\section{Procedimiento}

Los datos fueron introducidos y validados en una base de datos electrónica en el programa spss-18. Se realizaron análisis descriptivos para calcular proporciones, así como pruebas de correlación de Pearson para analizar relaciones entre variables y la edad.

\section{Resultados}

Gran parte de los estereotipos e imágenes en torno a la vejez giran en torno a la salud de las personas mayores, en el sentido generalizado de que son personas enfermas y dependientes.

En este sentido, los datos de este estudio demuestran que, efectivamente, la gran mayoría de las personas padecen alguna enfermedad (94.5\%), las más comunes hipertensión arterial (62.5\%), enfermedades de los huesos o articulaciones (62.5\%), diabetes (25.9\%) e hipercolesterolemia (31.2\%); sin embargo, la mayoría de las personas reportó una autopercepción positiva acerca de su salud (60.1\%) y no se encontró una relación entre el número de enfermedades reportadas y la edad $(r=-.010, p=.802)$.

Más aún, la condición de salud no es necesariamente indicador de dependencia, ya que se encontró que $70.2 \%$ de las participantes eran autónomas e independientes para llevar a cabo actividades instrumentales de la vida diaria, en contraparte con sólo $20.8 \%$ que dependía de otras personas para hacer la compra, $8.6 \%$ para preparar la comida, $8 \%$ para usar medios 
de transporte, 5.8\% para usar el teléfono, 5.2\% para tomar sus medicamentos, 3.8\% para lavar la ropa, 3.4\% eran dependientes en la actividad de limpiar la casa y solamente $3.1 \%$ para manejar su propio dinero. Solamente $2.8 \%$ de las participantes eran dependientes para llevar a cabo las actividades básicas de la vida diaria (bañarse, arreglarse, comer, vestirse, deambular, trasladarse, usar el baño, entre otras). Se encontró una correlación negativa entre la funcionalidad física y la edad, tanto para las actividades instrumentales $(r=-.292, p=.000)$ como básicas de la vida diaria $(r=-.188, p=.000)$.

Con respecto al funcionamiento cognitivo de las personas mayores, se encontró que del total de las participantes, solamente $13.6 \%$ tenía deterioro cognitivo, es decir, $86.4 \%$ conservan sus capacidades de cálculo, memoria, lenguaje, y orientación en un rango normativo según su edad. Se encontró una correlación negativa entre el funcionamiento cognitivo y la edad ( $r=$ $-.272, p=.000)$.

Referente al estado anímico, en este estudio $72.4 \%$ refirió estar anímicamente saludable, y a pesar de que $27.6 \%$ de las participantes reportó sintomatología depresiva, la mayoría de las personas mayores entrevistadas reportó satisfacción con la vida. Del total de las entrevistadas, $30.4 \%$ señaló estar muy satisfecha con su vida en la actualidad, $37.8 \%$ reportó bastante satisfacción, $29 \%$ dijo estar algo satisfecha y solamente $2.8 \%$ aseveró estar nada satisfecha. No se encontró correlación entre la sintomatología depresiva y la edad $(r=.075, p=.060)$.

Con respecto a la productividad, al momento del estudio, $14.4 \%$ de las personas mayores participantes seguían activas laboralmente, principalmente en trabajos no calificados $(7.5 \%)$ o como vendedoras (4.4\%), mientras que la gran mayoría reportó ser ama de casa (85.6\%). La gran mayoría era dueña de su vivienda (72.3\%) que compartía con su esposo (21.9\%), pero principalmente con sus hijos y/o sus familias (59.3\%). Las actividades que desarrollaban principalmente eran las propias del quehacer del hogar (85.5\%), aunque algunas realizaban actividades intelectuales como leer (12.1\%), artísticas (10.8\%), de participación social (34\%) y gran parte realizaba actividades de 
ocio (55.5\%), principalmente asistir a reuniones familiares. Se encontró una correlación negativa entre la realización de actividades y la edad $(r=-.245, p=.000)$.

\section{Discusión}

En este estudio, las imágenes acerca de la vejez con respecto a la salud, funcionalidad, estado cognitivo y anímico y productividad comúnmente compartidos por la sociedad no corresponden a la situación actual reportada por los propios adultos mayores.

Si bien se encontró que la mayoría de las personas mayores tiene al menos una enfermedad, el número de padecimientos no está relacionada con la edad, es decir, que probablemente las enfermedades están asociadas a los estilos de vida más que a la condición de la edad. Además, la autopercepción de la salud en general es muy positiva, lo cual es importante debido a que se ha encontrado que la buena salud subjetiva es un factor que predice menor mortalidad, declive funcional y demanda de servicios de salud (Zikic, Jankelic, Milosevic, Erceg y Davidovic, 2009).

Contrario al estereotipo de dependencia, las personas mayores en general fueron funcionalmente independientes, es decir, pueden valerse por sí mismas, autocuidarse y llevar una vida funcional en su comunidad. Adicionalmente, en su gran mayoría reportaron estar cognitivamente intactas y con un estado anímico saludable, es decir, no son "seniles" o con problemas de memoria que los lleven hacia la demencia y, a pesar de ser percibidos como tristes y deprimidos, las personas mayores reportan altos índices de satisfacción con la vida y bienestar en general, cualidades que les pueden permitir adaptarse y funcionar socialmente.

La correlación negativa entre la funcionalidad física y el funcionamiento cognitivo indican que conforme aumenta la edad tanto el desempeño físico como cognitivo disminuyen; sin embargo, está bien documentado que en el envejecimiento cognitivo existe un declive considerado normal, en el que algunas funciones cognitivas se mantienen estables mientras que otras 
declinan como parte del envejecimiento normal. Estos cambios cognitivos asociados a la edad le ocurren a las personas que no tienen patologías; además, dichos cambios no interfieren con la capacidad para participar en las actividades cotidianas (Anderson, Murphy y Troyer, 2012).

Finalmente, la evidencia muestra que las personas mayores son más productivas de lo que se les percibe, aunque no de manera remunerada por medio de un trabajo, sino que ofrecen a la familia servicios, como proveer una vivienda y dedicarse a los quehaceres del hogar, actividades que representan un ahorro a la economía familiar.

\section{Referencias}

Anderson, N.D., Murphy, K.J. y Troyer, A.K. (2012). Living with Mild Cognitive Impairment. A Guide to Maximizing Brain Health and Reducing Risk of Dementia. N.Y.: Oxford University Press.

Folstein, M., Folstein, S. y McHugh, P. (1975). "Mini-Mental State": a Practical Method for Granding the Cognitive State of Patients for the Clinician. Journal of Psychiatric Research, 12, 189-198.

Lawton y Brody. (1969). Philadelphia Geriatric Center-Instrumental Activities of Daily Living. Escala de Lawton y Brody (PGC-IADL). En M.V. Lucas-Vaquero (Coord.), Compilación de técnicas para una evaluación multidimensional en la vejez. España: UAB.

Levy, B.R., Slade, M.D. y Kasl, S.V. (2002). Longitudinal Benefit as Positive Self-Perceptions of Aging on Functional Health. Journal of Gerontology Psychological Sciences, 83, 261-270.

Mahoney, F.I. y Barthel, D. (1965). Functional Evaluation: The Barthel Index. En M.V. Lucas-Vaquero (Coord.), Compilación de técnicas para una evaluación multidimensional en la vejez. España: UAB.

Ory, M., Kinney Hoffman, M., Hawkins, M., Sanner, B. y Mockenhaupt, R. (2003). Challenging Aging Stereotypes: Strate- 
gies for Creating a More Active Society. American Journal of Preventive Medecine, 25, 164-171.

Sindi, S., Juster, R., Wan, N., Nair, N., Ying Kin, N. y Lupien, S. (2012). Depressive Symptoms, Cortisol and Cognition during Human Aging: The Role of Negative Aging Perceptions. Stress: The International Journal on the Biology of Stress. 15(2), 130-137.

Yesavage, J.A., Brink, T.L., Rose, T., Lum, O., Huang, V., Adey, M. et al. (1983). Development and Validation of a Geriatric Depression Screening Scale: A Preliminary Report. Journal of Psychiatric Research, 17(1), 37-49.

Zikic, L., Jankelic, S., Milosevic, D.P., Erceg, P. y Davidovic, M. (2009). Self-perception of Health in the Oldest-Old Subjects. Archives of Gerontology \& Geriatrics, 49, 245-249. 
